\title{
Protección jurídica de la materia biológica vegetal. Transgénicos, patentes y obtenciones vegetales*
}

\author{
Juliana Morais de Carvalho Castiglioni** \\ Nivaldo dos Santos ${ }^{* * *}$ \\ Pablo Amat Llombart ${ }^{* * *}$ \\ Recibido: julio de 2016 \\ Aprobado: septiembre de 2016 \\ DOI: 10.22395/ojum.v15n30a7
}

\section{RESUMEN}

La relevancia del tema abordado se basa en el conocimiento del régimen jurídico sobre la protección de la materia biológica vegetal y las variedades vegetales, dada su relevancia e implementación práctica en el campo de la innovación agroalimentaria y del comercio internacional. En primer lugar, se aporta claridad científica a los conceptos y definiciones legales acerca de las variedades y obtenciones vegetales y los organismos transgénicos. Seguidamente, partiendo del Derecho internacional convencional (Tratados), se examinan diversos modelos jurídicos para la protección legal de nuevas variedades y de material vegetal (Unión Europea/España, con especial énfasis en Brasil). Se estudian también las sincronías y desajustes entre los dos posibles sistemas jurídicos de protección: título de obtención vegetal y patente de invención. Finalmente se analiza el desarrollo a nivel mundial de las solicitudes y títulos sobre obtenciones vegetales.

Palabras clave: Propiedad industrial; obtenciones vegetales; patentes; organismos transgénicos; regulación legal.

Este artículo constituye un avance de la investigación sobre propiedad industrial en la agricultura del Máster en Derecho Agrario de la Universidad Federal de Goiás (Brasil), donde la coautora defendió la tesina titulada "Protección y transferencia de tecnologías verdes", financiada con beca por la FAPEG. También supone una aportación a una de las líneas de investigación universitaria "Biotecnología, protección legal y agricultura" de los otros coautores.

* Graduada en Publicidad por la Universidad de Brasilia y en Derecho por la PUC-GO. Máster en Derecho Agrario por la Universidad Federal de Goiás (Brasil).e-mail: jmcpub@gmail.com

... Profesor del Máster en Derecho Agrario y de la Facultad de Derecho de la Universidad Federal de Goiás. PHD en Derecho por la PUC MG. Doctorado en Derecho por la PUC SP. Máster en Historia de las Sociedades Agrarias UFG. E-mail: nivaldodossantos@bol.com

*..* Licenciado en Derecho por la Universidad de Valencia (España). Doctor en Derecho por la Universidad Politécnica de Valencia (UPV). Profesor Titular de Derecho Civil de la UPV. Vicepresidente de la Unión Mundial de Agraristas Universitarios. Delegado del Comité Europeo de Derecho Rural. Vicepresidente de la Asociación Española de Derecho Agrario. E-mail: pabamllo@urb.upv.es 


\title{
Legal Protection Plant Biological Matter, Transgenic Products, Patents, and Plant Byproducts
}

\begin{abstract}
The relevance of the topic addressed is based on the knowledge of the legal system on the protection of plant biological mater and plant varieties, given its importance and practical implementation in the field of agricultural and food innovation and international trade. First, the article provides scientific explanation to legal concepts and definitions about plant varieties and byproducts and transgenic organisms. Second, and based on the conventional international law (treaties), several legal systems on the legal protection of new varieties and plant material (European Union / Spain, with special emphasis on Brazil) are analyzed. Synchronies and malfunction between the two potential legal systems on protection (plant byproducts title and invention patent) are also studied. Finally, the world development of requests and titles on plant byproducts is analyzed.
\end{abstract}

Key words: industrial property; plant byproducts; patents; transgenic organisms; legal regulation. 


\section{INTRODUCCIÓN}

Los recientes avances de las nuevas tecnologías, entre los que destaca la ingeniería aplicada a la genética (humana, animal, vegetal...), han venido provocando en las últimas décadas cambios relevantes en la forma de pensar, así como en el modo de vida de la sociedad. De hecho, dichas nuevas investigaciones y sus aplicaciones han sido capaces de provocar cambios no solo en los hábitos de consumo, sino también en la relación entre hombre y naturaleza. Y por cuanto afecta al campo de la agricultura, el referido proceso tecnológico y su aplicación al ámbito de la biología agroalimentaria han devenido en importantes cambios sobre ciertos cultivos en determinados países desarrollados y en vías de desarrollo.

La cuestión relativa a la selección de las plantas es importante para comprender los actuales derechos sobre las plantas y variedades vegetales analizados en este trabajo (vid. Amat Llombart, 2001). Así, la creación y desarrollo de nuevas variedades vegetales constituye una actividad que posibilita mejorar la calidad del producto final, los rendimientos unitarios de los cultivos, la resistencia a enfermedades, a plagas o a condiciones adversas, y facilita la mecanización, belleza y armonía en las formas y colores de plantas y flores (Amat Llombart, 2007, p. 17).

En efecto, las modernas posibilidades de control y transformación que trae consigo la biotecnología, y en particular la ingeniería genética, han producido una extraordinaria extensión del dominio humano so- bre los procesos de la naturaleza: la vida como objeto de manipulación. A partir de tales hallazgos el hombre adquiere la capacidad de injerencia en la vida y en la percepción del mundo de un modo nunca antes imaginado (Benthien, 2008).

Se puede afirmar que la manipulación de la vida y de la naturaleza por parte del hombre constituye una materia relacionada con distintas áreas de conocimiento, como pueden ser la ética, la biología, la química, la agronomía y también el derecho.

Pero, como bien se ha advertido, la protección de la materia viva vegetal corre el riesgo de limitarse a actuar en el mero juego del mercado, persiguiendo el ánimo de lucro, y de tal forma podría reducirse el significado de la vida y de la naturaleza a causa de la información que se puede extraer de ellas y de su utilización en sentido comercial (Benthien, 2008).

Por otro lado, no hay que olvidar que el progreso de las sociedades modernas no puede ni debe obstaculizar el avance de la ciencia, la tecnología y la ingeniería genética. Ahora bien, resulta necesario conocer en profundidad su alcance conceptual, sus potencialidades, sus beneficios, los riesgos ambientales y sociales que conlleva, así como su regulación legal. Todos ellos constituyen elementos fundamentales para la adecuada gestión y protección de la actual sociedad moderna y globalizada.

La biotecnología y la nanotecnología son sectores que muchos analistas conside- 
ran como el principal motor del cambio tecnológico, generador de profundos efectos sobre el desarrollo económico y social. En efecto, pueden y deben contribuir a abordar los grandes retos que afronta la humanidad en las próximas décadas: seguridad alimentaria, suministro energético, cambio climático, salud, además de productividad y calidad en la agricultura (Camacho, 2010).

El presente trabajo analiza principalmente la regulación relativa a la materia viva vegetal en un país latinoamericano con amplio perfil agroalimentario como es Brasil. También se añaden referencias puntuales comparadas con la normativa de la Unión Europea y de España. En líneas generales, la metodología aplicada a la investigación atiende a la usualmente utilizada en el campo de las ciencias jurídicas, incluyendo el estudio comparado de la legislación, la jurisprudencia y el análisis de casos.

En primer lugar, el artículo trata de aportar luz a los conceptos y definiciones legales de las obtenciones vegetales y organismos transgénicos. También examina diversos modelos jurídicos adoptados para la protección de la materia vegetal en un contexto globalizado (si bien principalmente el sistema brasileño). Estudia la posibilidad de una doble vía de protección jurídica dispensada a la materia biológica o vegetal, bien mediante el título de obtención vegetal o bien mediante el certificado de patente de invención. Finalmente, se analiza en particular el panorama jurídico relativo a las obtenciones vegetales.
En definitiva, el objetivo se centra en conocer con mayor profundidad las características, avances y retos que afronta el marco jurídico de la protección de las variedades vegetales y la materia viva vegetal. Tal aportación científica puede facilitar la labor de diferentes actores sociales implicados en este ámbito, tales como investigadores, empresarios, funcionarios públicos, políticos y profesionales del derecho. En definitiva, no cabe la menor duda de la actualidad y relevancia del tema abordado, en su relación con la propia vida, la naturaleza, la innovación y el desarrollo social.

\section{ORGANISMOS TRANSGÉNICOS, VARIEDADES VEGETALES Y OBTENCIONES VEGETALES}

Resulta imprescindible facilitar la comprensión de determinados conceptos cuando se pretende profundizar un tema complejo, vinculado a la ciencia, la biotecnología y la ingeniería genética aplicada, en el que se manejan términos tales como organismos modificados genéticamente (OMG), variedades y obtenciones vegetales, etc.

En ese sentido, se entiende por OMG todo organismo que ha experimentado una alteración en su material genético con la finalidad de conseguir ciertas mejoras biológicas, agronómicas o comerciales. Se trataría de un concepto más amplio, ya que, por otra parte, un organismo transgénico viene definido por el hecho de haber recibido uno o más genes de otra especie o ser vivo (según la RAE "organismo vivo que ha sido modificado mediante la adición de genes exógenos para lograr nue- 
vas propiedades"). En su aplicación a los cultivos agrícolas, nos encontramos con variedades vegetales caracterizadas por la introducción de mejoras en su propio genoma, a fin de aportar diversas aplicaciones agronómicas y/o alimentarias al producto final. Cuestión más delicada y hoy día muy controvertida es la introducción de alimentos transgénicos en el mercado para el consumo humano, como veremos. Entre las definiciones legales, según el ordenamiento jurídico español se considera «Organismo modificado genéticamente» "cualquier organismo, con excepción de los seres humanos, cuyo material genético ha sido modificado de una manera que no se produce de forma natural en el apareamiento o en la recombinación natural, siempre que se utilicen las técnicas que reglamentariamente se establezcan" (artículo 2.b) de la Ley 9/2003, de 25 abril, por la que se establece el régimen jurídico de la utilización confinada, liberación voluntaria y comercialización de organismos modificados genéticamente).

Hay una clara distinción técnica y jurídica entre las variedades vegetales en las que se producen mejoras genéticas mediante procedimientos naturales o convencionales, sin provocar el trasvase genético entre especies (transgénesis), y aquellos otros supuestos de especies genéticamente modificadas mediante biotecnología o ingeniería genética (OMG o transgénicos). En efecto, en el primer caso no se aplica la legislación especial sobre OMG, de plena vigencia para el segundo supuesto. Así queda claramente plasmado en el artículo 1 (Objeto y ámbito de aplicación) de la citada Ley 9/2003 de España.
Y por lo que afecta al caso de Brasil, este inmenso país constituye el segundo mayor productor de OMG en el mundo, solo superado por Estados Unidos (James, 2015), pero, a la vez, el mayor consumidor de pesticidas. Por ello, y pese a los avances en las modernas técnicas de ingeniería genética, cabría preguntarse por qué Brasil se constituye en el mayor consumidor de pesticidas del mundo ¿Es posible efectuar una comparación entre la demanda de pesticidas vinculada al uso de variedades transgénicas, por un lado, y a las obtenciones vegetales, por otro? En todo caso no se puede basar el análisis en generalizaciones, pues la respuesta depende específicamente de la especie vegetal de que se trate. Sin embargo, un dato relevante a tener en cuenta es el hecho de que las mismas empresas multinacionales que comercializan semillas y plantas transgénicas sean las que al mismo tiempo distribuyan ciertos plaguicidas especialmente adaptados a tales semillas y cultivos.

Según el último informe disponible del ISAAA (International Service for the Acquisition of Agri-biotech Applications), que recoge los datos de 2015, Estados Unidos lidera la producción mundial del cultivo de variedades agrícolas transgénicas (70,9 millones de ha). Brasil, en segundo lugar, cultiva 44,2 millones de ha, con un incremento de 2 millones de hectáreas más en 2015 que en 2014. Le siguen Argentina (24,5 mill. / ha), India (11,6 mill. / ha), Canadá (11 mill. / ha) y China (3,7 mill. / ha). En Brasil, la tasa de adopción fue del 89,3\%, siendo la soja, el maíz y el algodón los tres cultivos trans- 
génicos aprobados comercialmente en el país. En el caso de la soja, el 93\% de la superficie fue plantada con variedades transgénicas de cultivos de invierno y verano; respecto al maíz, la tasa fue del $82 \%$ y en cuanto al algodón, del $66 \%$. Por su parte, España sembró el 92\% de todo el maíz biotecnológico, lideró la Unión Europea con 107,749 hectáreas de maíz Bt, pero con una caída del $18 \%$ respecto de las 131.518 hectáreas sembradas en 2014. Al nivel mundial, tras un notable período ininterrumpido de 19 años consecutivos de crecimiento anual desde 1996 hasta 2014, la superficie mundial anual de cultivos biotecnológicos alcanzó un pico de 181,5 millones en 2014, comparado con los 179,7 millones de hectáreas sembradas en 2015 por 28 países. La superficie mundial de cultivos biotecnológicos aumentó 100 veces de 1,7 millones de hectáreas en 1996 a 179,7 millones de hectáreas en 2015, con un máximo de 17 a 18 millones de agricultores, lo cual determina que los cultivos biotecnológicos sean la tecnología agrícola de mayor tasa de adopción durante los últimos tiempos (James, 2015).

Los datos arriba expuestos no dejan duda sobre la consolidada implantación de los OMG en el sector agroalimentario desde hace más de 20 años en todo el mundo. Con todo, el debate sobre el uso de la tecnología transgénica aplicable a la producción de plantas, vegetales y alimentos sigue de rabiosa actualidad y relevancia. Podemos hallar argumentos positivos o negativos, a favor o en contra del uso de dicha biotecnología, todos ellos infiltrados de una fuerte carga ideológica y social.
Por un lado, entre los argumentos a favor de los transgénicos, encontramos motivaciones tales como el aumento de la productividad agrícola (ante la necesidad de proveer al mundo de más cantidad de alimentos, con base en el aumento de la población y en los objetivos del milenio de la ONU, entre los que se encuentra la lucha contra el hambre en el mundo), la mejora en las condiciones de crecimiento, la disminución en el uso de plaguicidas y fitosanitarios (mejoras ambientales), así como la reducción de los costes de producción. Las principales modificaciones genéticas están diseñadas para lograr que las nuevas variedades vegetales resulten más resistentes a los pesticidas, combatan mejor las plagas y superen las condiciones climáticas adversas (sequía, etc.). Para lograr niveles elevados de competitividad agroindustrial sería necesaria la adopción masiva de los cultivos transgénicos.

Por otro lado, hallamos también argumentos en contra. Cabe poner como ejemplo el caso de la soja RR (Roundup Ready), aprobada en Brasil en 1998 con fines de comercialización por la empresa Monsanto. Posee como característica su tolerancia a los herbicidas, siendo el «glifosato» el principal ingrediente. Sin embargo, la introducción de esta variedad y sistema de cultivo ha contribuido a la aparición de malas hierbas resistentes al glifosato, provocando que los agricultores sufran el aumento en el coste de producción debido al incremento en la necesidad de aplicación del herbicida Roundup u otro (Ferreira, 2013). 
Siguiendo con el ejemplo brasileño, según la opinión de Gabriel Bianconi (investigador de la AS-PTA -Familia Agroecología y Agricultura-), tras la liberalización de la utilización de productos transgénicos en Brasil, el país se ha convertido en uno de los que más utiliza "venenos agrícolas" en el mundo. Alerta del dominio de unas pocas grandes empresas en el mercado de semillas, de la contaminación de cultivos orgánicos (ecológicos) y de la creciente dificultad de producir alimentos no modificados genéticamente. Para este autor, Brasil posee perfectas condiciones para desarrollar su sistema agrícola mediante una producción de tipo familiar, que ya representa el 70\% del porcentaje básico de la producción alimentaria (según el Censo Agrícola de 2010) y mediante formas de producción de agricultura ecológica (Bianconi, 2013).

Otro concepto relevante a tener en cuenta es el de «obtenciones vegetales». Según el Ministerio de Agricultura, Ganadería y Abastecimiento de Brasil -MAPA-, las obtenciones vegetales constituyen el resultado de la mejora en una variedad de planta que la hace diferente de las demás en cuanto a su color, tamaño, resistencia a las enfermedades..., todo ello debido a una nueva combinación de su propio material genético. La nueva característica debe estar presente y manifestarse de igual forma en todas las plantas de la misma variedad, manteniéndose inalterada a lo largo de las sucesivas generaciones o plantaciones.

Por lo tanto, de acuerdo con el apartado IV del artículo 3 de la Ley de Protección de
Obtenciones Vegetales brasileña -LPC(Ley 9456, de 25 de abril de 1997), «obtención vegetal» es la variedad de cualquier género o especie vegetal superior que sea claramente distinguible de otras variedades vegetales conocidas por un número mínimo de descriptores, por su propia denominación, que sea homogénea y estable en cuanto a los descriptores través de las generaciones sucesivas y sea una especie susceptible de uso por el sistema agroforestal, descrita en una publicación especializada disponible y accesible para el público, así como el linaje componente de los híbridos.

Así pues, fomentar la protección de semillas y variedades vegetales en el marco de la innovación tecnológica aplicada y la competitividad en favor del desarrollo del país, es plausible en el contexto de la globalización y la generación de conocimiento. Según se afirma, la riqueza adopta formas intangibles. El capital intelectual de las empresas, la sociedad y el Estado se convierte en la base para establecer el nivel de competitividad y la seguridad alimentaria. Dentro de este ámbito debe incardinarse el sistema de protección de obtenciones vegetales (Santos, 2012, p. 174).

En ese sentido, por un lado, al nivel socioambiental autores como Santilli (2009, p. 99) consideran que los criterios de la homogeneidad y la estabilidad, además de la necesidad de pruebas para evaluar el "valor agronómico y tecnológico" de las variedades agrícolas, en última instancia, limitan y reducen la diversidad y la participación de los agricultores en 
esta tecnología. Las pruebas evalúan solo algunos de los caracteres, y se centran especialmente en los ingresos y la productividad. Sin embargo, se corre el riesgo de llegar a que se anule la diversidad de ambientes debido a una artificialidad extrema causada por el uso intensivo de pesticidas y fertilizantes químicos (...) sin tener en cuenta los contextos sociales y ambientales.

$\mathrm{Al}$ respecto, otros autores han puesto de manifiesto la necesidad de abordar políticas legislativas y estrategias públicas para preservar valores colectivos comunes como el medio ambiente y la agricultura, a la vez que se lucha contra los efectos del cambio climático (Amat Llombart, 2011, pp. 119 y ss.). También Barrigossi et al. (2004).

Del mismo modo, los opositores a este sistema de protección de la tecnología aplicada a las variedades vegetales esgrimen argumentos tales como la distribución, la concentración y la desnacionalización de los productores de semillas, la exclusión de los pequeños agricultores, desconociendo y desprotegiendo sus intereses (en relación con la agroindustria), la reducción de conocimientos tradicionales acerca de las semillas tradicionales, además de la limitación de la herencia genética vegetal y la biodiversidad (Araújo, 2010, pp. 43 y 44).

El propio Araújo (2010, p. 54), a propósito del eventual riesgo de reducción del patrimonio genético de la agricultura brasileña, apunta que la posibilidad de que se produzca un proceso de erosión genéti- ca parece ser incapaz de materializarse como resultado de la aplicación de la LPC. Tal posibilidad puede ser una amenaza, independientemente de la existencia o no de un sistema legal de protección de obtenciones vegetales. Se trata más bien de una cuestión que afecta más bien a una política adecuada para la preservación y ampliación de la base genética de las plantas del país, que propiamente el resultado de la concentración de la investigación sobre las variedades de mayor interés comercial.

\section{LA REGULACIÓN LEGAL INTERNACIONAL Y SISTEMAS NACIONALES}

Abordamos seguidamente una aproximación al régimen jurídico de la protección industrial (patentes, obtenciones vegetales) sobre plantas y materia biológica vegetal, para lo cual tenemos que partir necesariamente del hecho de que en este ámbito material los acuerdos internacionales suscritos y ratificados por los Estados soberados resultan fundamentales.

Así, el 20 de marzo de 1883 fue suscrito el Convenio de París para la protección de la propiedad industrial, por virtud del cual se constituyó la Unión Internacional para la Protección de la Propiedad Industrial. Sin embargo, en esa época inicial la protección de las invenciones nuevas estaba más bien pensada para inventos mecánicos y de fabricación industrial, prestando nulo o escaso interés a la tutela de las "invenciones sobre plantas o vegetales".

Fue por ello que al nivel nacional se fueron aprobando diversas legislaciones para pa- 
liar dicha ausencia de protección jurídica e incentivar, a la vez, la investigación en biología agrícola vegetal. Así, por ejemplo, la Ley de patentes sobre plantas de Estados Unidos de 1930 (Ley Townaws-Purnell o Plant Patent Act) (vid. Sánchez Gil, 1998) otorga una protección especial estableciendo derechos de patente en favor de los obtentores de nuevas variedades de una gran cantidad de plantas reproducidas asexualmente. Posteriormente, en el área europea, durante la década de 1950 países como Alemania y Francia pusieron en vigor una protección sui géneris para las obtenciones vegetales.

Las diversas iniciativas nacionales y la necesidad de crear un sistema jurídico propio y homogéneo de nivel internacional dieron lugar a la Conferencia de París, celebrada el 2 de diciembre de 1961 (MAPA, 2011), por la que se creó la Unión Internacional para la Protección de las Obtenciones Vegetales (UPOV), organización intergubernamental con sede en Ginebra (Suiza), y que fue el fruto del Convenio Internacional para la Protección de las Obtenciones Vegetales ("Convenio de la UPOV"). La misión de la UPOV es proporcionar y fomentar un sistema eficaz para la protección de las variedades vegetales con miras al desarrollo de obtenciones vegetales en beneficio de la sociedad.

La normativa internacional viene marcada por el Convenio para la protección de las obtenciones vegetales (UPOV) de 2 de diciembre de 1961, revisado en Ginebra el 10 de noviembre de 1972, el 23 de octubre de 1978 y el 19 de marzo de 1991. Tiene como objetivo fomentar el desarrollo de nuevas obtenciones para beneficio de la sociedad a fin de promover un sistema eficaz de protección de variedades vegetales. El Convenio de la UPOV es el fundamento en que se apoyan los miembros para fomentar el fito-mejoramiento mediante la concesión a los obtentores de variedades vegetales de un derecho de propiedad intelectual: el derecho de obtentor.

Siguiendo con el derecho internacional, también cabe mencionar los acuerdos sectoriales del GATT, aprobados en Marrakech el 15 de abril de 1994, donde se constituyó la Organización Mundial del Comercio (OMC), destacando la aprobación del Acuerdo sobre los Aspectos de los Derechos de Propiedad Intelectual relacionados con el Comercio (ADPIC). El ADPIC, negociado en la Ronda Uruguay del GATT (1986-1994), incorporó normas sobre la propiedad industrial en el sistema multilateral de comercio y supuso un intento por reducir las diferencias en el modo de proteger tales derechos en los distintos países, tratando de someterlos a normas internacionales comunes y homogéneas. Además, en caso de surgir diferencias comerciales respecto a los derechos de propiedad industrial, los Estados pueden recurrir al sistema de solución de diferencias de la OMC.

Dentro de dicho marco jurídico internacional (así la sección 5. a del Acuerdo ADPIC que se ocupa de las patentes: vid. artículo 27.3), se estableció que los países miembros de la OMC podrían regular la protección de la propiedad industrial de las obtenciones vegetales mediante un 
sistema de patentes, un sistema eficaz sui géneris o una combinación de ambos.

En aplicación del acuerdo internacional, algunos países como Estados Unidos, Japón, Australia y Corea, han optado por establecer un sistema de protección mixto de las variedades vegetales, que combina el sistema de patentes y una protección sui géneris. Otros países como Brasil o España han previsto exclusivamente un sistema de protección sui géneris (el de las obtenciones vegetales), como veremos.

En el caso de la Unión Europea (derecho comunitario) existe normativa específica relativa a la protección de las obtenciones vegetales. Nos referimos al Reglamento (CE) 2100/1994, de 27 de julio, del Consejo relativo a la protección comunitaria de las obtenciones vegetales (vid. Quintana Carlo, 1995), el cual está adaptado a las disposiciones básicas del Convenio UPOV en su versión de 1991. En su virtud, los Estados miembros podrán conceder derechos de propiedad nacionales sobre las variedades vegetales (artículo 3), si bien se prevé la prohibición de doble titularidad (artículo 92.1): "Ninguna variedad que sea objeto de una protección comunitaria de obtención vegetal podrá ser objeto de una protección nacional de obtención ni de patente alguna para tal variedad". O sea, el obtentor deberá optar entre el ámbito comunitario o el nacional en el momento de solicitar la concesión de la protección jurídica (Amat Llombart, 2007, p. 25).

El Reglamento 2100/1994, en su artículo 19 , establece plazos distintos a los del
Convenio UPOV de 1991 (aumentados en cinco años). Así el derecho del obtentor tiene una duración de 25 años, por regla general, o de 30 años, en el caso de variedades de vid y de especies arbóreas.

Por su parte, España se incorporó como miembro integrante del Convenio UPOV en 1980. El Acta UPOV de 1991 entró en vigor el 24 de abril de 1998 en países como Holanda, Dinamarca, Suecia, Israel, Bulgaria y Rusia (Amat Llombart, 2007, p. 20).

A partir de ahí España aprobó la Ley 3/2000, de 7 de enero, de régimen jurídico de la protección de las obtenciones vegetales (vid. Quintana Carlo, 1999), desarrollada mediante Real Decreto 1261/2005, de 21 de octubre (Reglamento de protección de obtenciones vegetales). Además, existe la Ley 24/2015, de 24 de julio, de patentes y la Ley 9/2003, de 25 de abril, que establece el régimen jurídico de los organismos modificados genéticamente, así como su Reglamento general aprobado por Real Decreto 178/2004, de 30 de enero (vid. Amat Llombart, 2007). En este último ámbito material, el régimen jurídico de los organismos, alimentos y piensos modificados genéticamente ha sido ampliamente estudiado por la doctrina, analizando todas las fases que van desde la utilización confinada, a la liberación intencional o voluntaria en el medio ambiente y hasta la comercialización, etiquetado y trazabilidad de tales productos (Amat Llombart, 2008, p. 167 y ss.).

Pasando al ordenamiento jurídico brasileño, y yendo atrás en el tiempo, el primer 
antecedente de la protección de las obtenciones vegetales en Brasil lo hallamos en el Código de Propiedad Industrial de 1945, al que se refieren las regulaciones posteriores. Más adelante, en presencia de dos posibles modelos jurídicos disponibles para regular la materia, Brasil optó por la tutela exclusiva de un sistema específico para las obtenciones vegetales (versión del Convenio UPOV de 1978). Por otra parte, el citado artículo 27.3 del Convenio ADPIC fue introducido en Brasil el 14 de mayo de 1996 por la Ley de Propiedad Industrial 9279, la Ley de Semillas y la Ley de Protección de Cultivares (LPC) 9456 de 1997. Mediante tal legislación se ratificó el modelo sui géneris de protección de las obtenciones vegetales. Dicha normativa fue complementada por el Decreto 2366, de 5 de noviembre de 1997 y el Decreto Legislativo 28, de 19 de abril de 1999, con base en el texto del Acta del Convenio UPOV de 1978. Más tarde, tras aprobarse el Acta del Convenio UPOV de 1991, las modificaciones fueron introducidas mediante Decreto 3109, de 30 de junio de 1999. Además, cabe citar la Ley de Semillas 10.711, de 2003 y su Decreto 5153, de 23 de julio de 2004. Finalmente, la Ley de Innovación Tecnológica 10.973, de 2 de diciembre de 2004 (consúltese MAPA, 2011, p. 27).

En otro orden de cosas, de la normativa uniforme previamente analizada, se deriva la existencia de cinco requisitos básicos para que pueda dispensarse la protección a una variedad vegetal: la novedad, el carácter distintivo, la uniformidad, la estabilidad y la denominación propia (Bulsing et al., 2010, pp. 259 a 261).
Los formularios para las solicitudes de protección en Brasil son tres: solicitud electrónica, informe técnico y tabla de descriptores mínimos. Si bien se encuentran disponibles en el sitio web del SNPC, se requiere de la ayuda de expertos para completar el procedimiento.

Un aspecto influyente del procedimiento para la concesión del título de obtención vegetal es la necesidad de invertir tiempo suficiente para demostrar la estabilidad de las plantas a lo largo de sucesivas generaciones, tiempo de ordinario bastante prolongado, ciertamente, variando según las especies entre 10 y 30 años. Además, será preciso facilitar una muestra (puede ser cualquier parte de la planta, semillas, plantas de semillero, esquejes, meristemos...) que sea capaz de generar nuevas plantas de la variedad protegida.

En Brasil, la duración legal de la protección del Certificado de Obtención Vegetal se extiende como regla general hasta 15 años desde la fecha de concesión. En caso de árboles frutales, forestales, ornamentales y vides se extiende a 18 años.

Además, es importante añadir, finalmente, que las obtenciones vegetales en Brasil pueden ser protegidas y registradas también para uso comercial. Nos hallamos ante dos instituciones jurídicas distintas: la protección como obtención y la protección como variedad comercial. Para ser protegido (obtención) no hace falta estar registrado (variedad comercial), y viceversa. Se trata de inscripciones completamente independientes, pero solamente pueden ser instadas ante la autoridad 
competente por el obtentor con derecho de explotación comercial. Así el SNPC es la Administración responsable para la protección del derecho industrial y exige las pruebas de DHE para incluir la variedad en la lista nacional de obtenciones vegetales protegidas. Sin embargo, para la producción y el comercio son necesarias las pruebas de VCU (valor de cultivo y uso) en el RNC-Registro de Obtencionespara la lista de variedades comerciales.

\section{DOS POSIBLES SISTEMAS DE PROTECCIÓN EN EL ÁMBITO DE LA PROPIEDAD INDUSTRIAL: PATENTES Y OBTENCIONES VEGETALES}

Desde el punto de vista estrictamente jurídico, se puede afirmar que la materia biológica vegetal, en términos generales, es susceptible de obtener la protección legal por el sistema de patente de invención y por el sistema de obtención vegetal. La cuestión clave estriba en saber distinguir con nitidez el tipo de material vegetal presentado para optar a la tutela jurídica. Lo que resulta claramente prohibido es que un mismo material vegetal sea tutelado, a la vez, por un certificado de patente y por un título de obtención vegetal. Solo cabrá aplicar uno de ellos en atención al objeto protegible, como veremos seguidamente.

En el ámbito del derecho comunitario europeo y del derecho español, la cuestión quedó definida tras la aprobación y transposición a los ordenamientos internos de los países miembros de la UE de la Directiva 98/44/CE, de 6 de julio, sobre protección jurídica de las invenciones biotecnológicas (vid. Martín Uranga, 2003). En su virtud, hoy son patentables las invenciones que tengan por objeto "un producto compuesto de materia biológica o que contenga materia biológica, o un procedimiento mediante el cual se produzca, transforme o utilice materia biológica". También "la materia biológica aislada de su entorno natural o producida por medio de un procedimiento técnico podrá ser objeto de una invención, aun cuando ya exista anteriormente en estado natural" (artículo 4, Ley 24/2015 de patentes española). A dichos efectos, se entenderá por «materia biológica» aquella que contenga información genética autorreproducible o reproducible en un sistema biológico, y por «procedimiento microbiológicos aquel que utilice una materia microbiológica, que incluya una intervención sobre la misma o que produzca una materia microbiológica. Por otra parte, no podrán tampoco ser objeto de patente "las variedades vegetales y las razas animales. Serán, sin embargo, patentables las invenciones que tengan por objeto vegetales o animales, si la viabilidad técnica de la invención no se limita a una variedad vegetal o a una raza animal determinada" (artículo 5.2, Ley 24/2015).

Así pues, una nueva variedad vegetal tan solo podrá ser objeto del derecho de obtención vegetal, título jurídico que en España se regula por la Ley 3/2000, de 7 de enero, de régimen jurídico de la protección de las obtenciones vegetales. Por tanto, la clave, de nuevo, vuelve a situarse en la precisión que se otorgue a la definición del objeto protegible: la variedad vegetal nueva. Según el artículo 2 de la Ley $3 / 2000$, 
[...] se entiende por variedad un conjunto de plantas de un solo taxón botánico del rango más bajo conocido que, con independencia de si responde o no plenamente a las condiciones para la concesión de un derecho de obtentor, pueda: a) Definirse por la expresión de los caracteres resultantes de un cierto genotipo o de una cierta combinación de genotipos; b) Distinguirse de cualquier otro conjunto de plantas por la expresión de uno de dichos caracteres por lo menos, y c) Considerarse como una unidad, habida cuenta de su aptitud a propagarse sin alteración.

En suma, una variedad vegetal se caracteriza por la totalidad de su genoma, que la individualiza y diferencia claramente de otras variedades vegetales preexistentes.

Como vemos, existen diferencias entre uno y otro sistema jurídico de protección, y no solo en cuanto al objeto material susceptible de tutela, sino también en cuanto a sus requisitos. Así, mientras que para la concesión del derecho de patente son requisitos necesarios la novedad, la aplicación industrial, la inventiva y la suficiencia descriptiva, para el otorgamiento del Certificado de Obtención de Variedades Vegetales se requieren los requisitos de novedad, carácter distintivo, uniformidad, estabilidad y denominación propia (MAPA, 2011) (vid. Amat Llombart, 2001).

Por cuanto afecta al ordenamiento jurídico de Brasil, la Ley de Propiedad Industrial
(LIP) 9279, de 14 de mayo de 1996, permite el patentabilidad de microorganismos y de procedimientos transgénicos (según disponen el artículo 18, III y el 42, II) y prohíbe la patente sobre plantas vivas o sus partes (artículos 10, IX y 18, III).

Si bien la diferencia más evidente es la que atiende al objeto en sí mismo considerado:
[...] según la Ley de Patentes o la Ley de la Propiedad Industrial (Ley 9.279/1996) son patenta- bles los microorganismos y los procedimientos de modificación genética, por ejemplo, los genes resultantes de la ingeniería ge- nética; y la Ley de protección de obtenciones vegetales protege la planta superior (variedad), las semillas o esquejes (Santos, 2012, p. 178).

Es decir, los seres vivos naturales (ya en su totalidad o parte de ellos) y los materiales biológicos encontrados en la naturaleza (o incluso en forma aislada de ella), inclusive el genotipo y el germoplasma de cualquier ser vivo natural, así como los procesos biológicos naturales, no se consideran invenciones a efectos de su patentabilidad, según la LPI. Se exceptúan los microorganismos transgénicos, los cuales serán patentables si cumplen los tres requisitos de patentabilidad (novedad, actividad inventiva y aplicación industrial) y no se trata de meros descubrimientos.

Resulta necesario señalar que la ley establece una excepción autorizando la posibilidad de patentar procedimientos relativos a OMG u OMG en sí mismos, 
siempre que tales OMG expresen, mediante intervención humana directa y en su composición genética, una característica normalmente no alcanzable por la especie en condiciones naturales. Y, claro está, siempre que no se trate de meros descubrimientos y cumplan con los requisitos generales exigidos para las patentes.

Por lo tanto, en el sistema brasileño podrían darse casos de acumulación de derechos de propiedad industrial. Así, cabría sumar al derecho de patente un certificado de obtención vegetal sobre una misma planta derivada de un procedimiento de transgénesis.

En ese sentido, cabe destacar el dictamen del Tribunal de Justicia de Río Grande do Sul, confirmando la posibilidad de registrar patentes sobre microorganismos transgénicos, productos y procesos, incluyendo variedades de soja transgénica, y determinando una superposición legal entre la LPC y la LPI. En ese caso, se aplica el derecho a percibir regalías de una variedad vegetal transgénica, incluso para uso propio, ya que la salvaguardia especial no se aplica a las patentes:

Apelaçâo cível. Ação coletiva. Direito à propriedade intelectual. Soja transgência. Lei de patentes e lei de proteção de cultivares. Razões de agravos retidos afastadas e preliminares superadas. Suficiência do laudo pericial e ausência de nulidade da prova a afastar o acolhimento das razões dos agravos retidos. Preliminares superadas por julgamento no STJ. Afastamento da disciplina normativa do Código de Defesa do Con- sumidor, não aplicada ao caso em discussão nos autos. No mérito, ainda que a Lei de Patentes não permita a proteção decorrente de patentes para o todo ou partes de seres vivos, houve expressa exclusão desta proibição em relação aos micro-organismos transgênicos (art. 18, inc. III, da Lei de Patentes), justamente porque resultantes de um produto de intervenção cultural, por meio do invento. Possível a extensão dos efeitos da propriedade intelectual sobre micro-organismos transgênicos desde que atendam os critérios próprios à situação jurídica de patenteabilidade -no caso, a novidade, a atividade inventiva e a aplicabilidade à atividade industrial. Circunstância expressamente reconhecida, por certificados próprios, em relação ao produto ora discutido em juízo. Não há como excluir dos efeitos de proteção desta o produto do objeto de patente, por força da proteção conferida pelo art. 42 da Lei 9279/96. A doutrina, na interpretação mais correta da Lei de Patentes acerca de casos de propriedade intelectual, esclarece que o art. 42 da Lei 9.279/96, por meio de seus incisos, protege tanto o produto que é objeto direto da patente, como o processo ou o produto obtido diretamente pelo processo, caso seja este patenteado. Descabe excluir-se o direito de patentes sobre o produto de uma intervenção humana por técnica de transgenia -e que abranja todas as características próprias à proteção, inclusive quando isto ocorra sobre uma cultivar. E isto, porque ambas as Leis mencionadas são omissas na hipótese de sobreposição de 
situações. Quando uma variedade é desenvolvida pela técnica da transgenia -podendo, portanto, receber a proteção da Lei de $\mathrm{Pa}$ tentes- e sofre, posteriormente, uma melhora por via biológica, recebendo o certificado de cultivares, em tese, tem-se situação de duplicidade de proteção, algo que estaria vedado pelas disposições da UPOV referente à Convenção de 1978. (...) Com relação ao percentual de royalties estabelecido, a desproporção é apontada ainda na inicial, por meio de... "seja judicialmente estabelecido percentual não abusivo para adequadamente indenizar as demandadas, em índices que variam entre $0,06 \%$ a $0,10 \%$ sobre o valor da soja transgênica comercializada, preferindo o menor índice pelas razões anotadas" (...) (TJ-RS - AC: 70049447253 RS, Relator: Maria Claudia Cachapuz, Data de Julgamento: 24/09/2014, Quinta Câmara Cível - Serviço de Apoio Jurisdição, Publicação: 02/10/2014»).

Es necesario señalar que el voto particular de la ponente María Claudia Cachapuz, en el caso del fallo jurisprudencial arriba citado, discutió la posibilidad de la doble protección de derechos exclusivos (patentes y obtenciones). La ponente puso de manifiesto que la sentencia de primera instancia recogía la opción del ordenamiento jurídico relativa a la no aceptación de una doble protección limitada a los derechos de propiedad, con base en la firma del Convenio internacional de la UPOV sobre la situación legislativa en cuestión: "Brasil optó por la versión del Convenio UPOV de 1978, en la que se pro- híbe expresamente la doble protección de derechos exclusivos". En esa línea los investigadores Charlene María Coradini de Ávila Plaza y Nivaldo dos Santos consideran que
[...] la práctica abierta que permite el solapamiento entre las paten- tes y las obtenciones vegetales, que pone en práctica varias pro- tecciones sobre el mismo objeto inmaterial, resulta ilegal e incons- titucional porque entra en con- flicto con los caracteres especí ficos de los sistemas normativos que rigen la materia y perturba el sistema civil y constitucional (Santos, 2012).

Ciertamente estos argumentos decantaron la opinión disidente del juez Jorge Luiz Lopes do Canto, según señala Juliana Santilli, quien subrayó que la Ley de Obtenciones Vegetales, al amparo del Convenio UPOV 1978, recogía el llamado privilegio de los agricultores prohibiendo la doble protección.

Sin embargo, el ponente plantea una visión diferente de la doctrina y sostiene la capacidad de relativizar la prohibición de la superposición de sistemas. En definitiva, prevaleció en el juicio la posición según la cual cuando una variedad vegetal se desarrolla mediante técnicas de modificación genética, y puede, por tanto, recibir la protección de la Ley de Patentes, pero experimenta posteriormente una mejora por vía biológica, la eventual tutela de dicha variedad mediante el certificado de obtención vegetal, en teoría, sí plantea la situación de duplicidad en la protección legal. 
Por lo tanto, la indicada interpretación de la jurisprudencia revela la importancia del debate abordado en este apartado, manifestando también que el poder judicial ha hecho uso y citado a expertos que apoyan dicha posición jurisprudencial.

Finalmente, retomando las diferencias entre uno y otro sistema de protección, los trámites burocráticos requeridos ante el Instituto Nacional de Propiedad Industrial (INPI) resultan más numerosos y exigentes cuando se trata de organismos transgénicos o de patentes sobre procesos biológicos, porque el solicitante deberá informar al CGEN (Consejo de Administración de Patrimonio Genético) sobre la fecha de autorización respecto del proceso relativo a los recursos genéticos y el origen del material genético nacional, según ordena la resolución de la INPI. 134/2006. También deberá efectuar el depósito del material biológico, presentar una descripción detallada que contenga las propiedades esenciales de la materia viva, necesaria para su descripción completa, de acuerdo con las tecnologías relacionadas con la materia respectiva, considerada relevante para su perfecta caracterización. Tras el depósito en forma del cultivo viable, se someterá al seguimiento en cuanto a las diferencias características de la materia viva previamente descritas, tanto en su aspecto morfológico como fisiológico y/o bioquímico.

Y, en fin, el depósito también irá acompañado de una descripción de los medios y métodos óptimos para el cultivo del material vivo in vitro, así como de una lista de las secuencias biológicas (toda solicitud de patente que describa una secuencia de nucleótidos o aminoácidos, debe contener, además de la memoria descriptiva, las reivindicaciones, dibujos... y una sección separada llamada «lista de secuencias», inmediatamente después de las reclamaciones).

\section{LAS OBTENCIONES VEGETALES EN NÚMEROS}

Teniendo en consideración los diversos estudios presentados por la Organización Mundial de la Propiedad Intelectual (OMPI, 2014), resulta factible analizar diversos indicadores relativos a las patentes, modelos de utilidad, marcas, diseños industriales y a los títulos de obtenciones vegetales tramitados y concedidos en el tiempo.

Así, según los datos publicados por la OMPI, estamos asistiendo a un incremento en el número de solicitudes de patentes en el año 2013. (Ver figura 1)

China encabezó la lista con 825.000 solicitudes, seguida de Estados Unidos con 571.000. Brasil está en la lista de los 20 países que mayor número de registro de patentes solicitaron en 2013, con 30.000 solicitudes, lo cual supuso un aumento del 1,5\% respecto al año anterior. Se observa que al nivel mundial se concedieron en el año 2013 aproximadamente 1,1 millones de patentes (OMPI, 2014). (Ver figura 2)

Según el informe, en 2013 alrededor de 15.000 obtenciones vegetales fueron solicitadas en todo el mundo. De ellas un 47\% tuvo su origen en Europa, 24\% en 


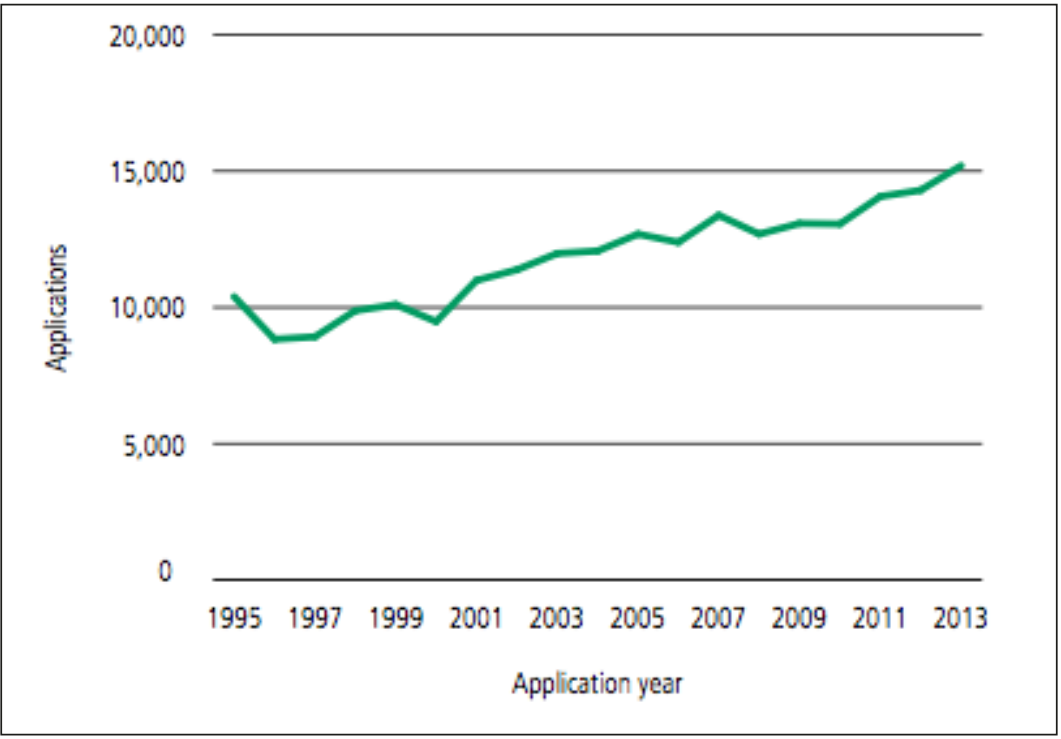

Figura 1. Solicitudes de patentes en el mundo. Periodo 1995-2013

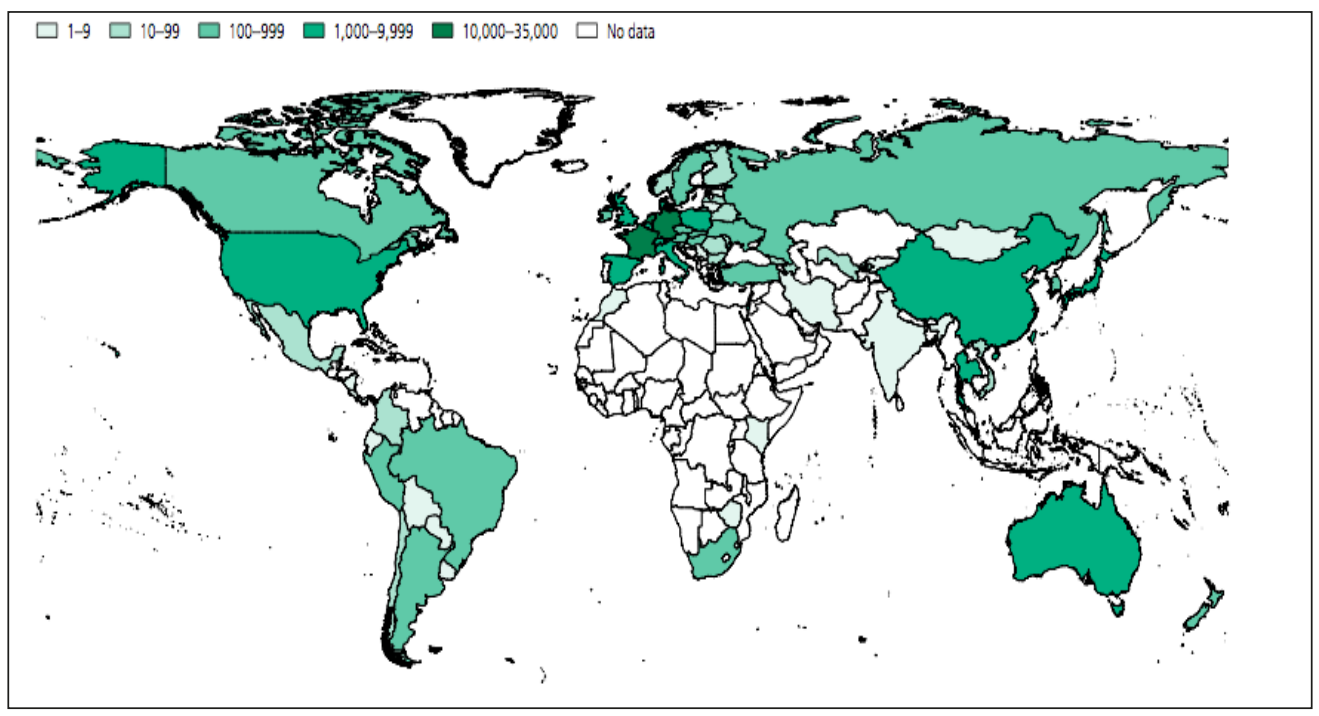

Figura 2. Mapa de solicitudes de obtenciones vegetales según origen. Año 2013 Fuente: OMPI, 2014, p. 133 
Asia, 14,5\% en América del Norte y un 8\% en América Latina. En particular, destaca la Oficina Comunitaria de Variedades Vegetales (OCVV) de la Unión Europea, receptora de más de 3000 solicitudes en 2013, y en particular países como Ucrania, China, Estados Unidos (con el formato de patente de plantas) y Japón (OMPI, 2014, pp. 130-135).

La OCVV y los EE. UU. representaron alrededor del $70 \%$ del crecimiento total de las obtenciones vegetales sobre variedades de plantas en vigor en todo el mundo en 2013. La mayoría de las 20 oficinas tenía más títulos en vigor en 2013 que en 2012. México $(+19,7 \%)$ y EE. UU. (+18,2\%) aumentaron en porcentaje. Por el contrario, Francia $(-13,6 \%)$ e Italia $(-10,2 \%)$ sufrieron disminuciones sustanciales (OMPI, 2014, p. 132). (Ver figura 3).

En el ámbito de la UE destaca la Oficina Comunitaria de Variedades Vegetales (OCVV o Community Plant Variety Office -CPVO-) responsable de implantar y aplicar el sistema de protección de obtenciones vegetales desde el 27 de abril de 1995. El 6 de diciembre de 1996, la Conferencia Intergubernamental de representantes de los Estados miembros (IGC) decidió establecer la sede de la Oficina en Angers (Francia). La Oficina es un organismo comunitario descentralizado que tiene personalidad jurídica propia. Se autofinancia principalmente con los ingresos procedentes de las distintas tasas que percibe (CPVO, 2015).

En el ámbito de la Unión Europea, una vez que la OCVV considera que los resultados del examen de una nueva variedad vegetal son satisfactorios y que se cumplen todos los demás requisitos, concede la protección comunitaria a la obtención vegetal por un plazo de 25 años, extendiéndose hasta 30 años, si se trata de vides y especies arbóreas.

Hasta el año 2015 se encontraban en vigor 23.771 títulos y derechos de obtenciones vegetales. Solo en 2015 fueron concedidos 2843 títulos. La gran mayoría afecta a variedades de plantas ornamentales (11.697), seguidas de variedades agrícolas (7209), hortalizas (3348) y frutas (1517 obtenciones vegetales titles granted - títulos concedidos) (CPVO, 2015.a).

Respecto a los títulos solicitados entre 1995 y 2016 (55.184 en total), la distribución sería la siguiente: $31.122(56,4 \%)$ de plantas ornamentales; 13.490 de variedades agrícolas (24,4\%); 7162 de hortalizas (13\%) y 3410 (6,2\%) de frutas. Por especies, aquellas que acumulan una gran cantidad de solicitudes desde 1995 en el campo de la agricultura son: Zea maus L (maíz, 4141); Triticum aestivum (trigo, 1595); Solanum tuberosum (patata, 1431), Brassica napus (colzal canola 1247) y Hordeum vulgare (cebada, 1132). Otros ejemplos de plantas ornamentales destacables son: rosa (3857) y chrysanthemum (3219) (CPVO, 2015).

Los test realizados a las obtenciones vegetales de la OCVV son llevados a cabo en cooperación con otros países, tales como Brasil, Israel, Colombia y Ecuador (CPVO, 2015).

Por lo que atiende a la situación en Brasil, según el SNPC (Servicio Nacional de 


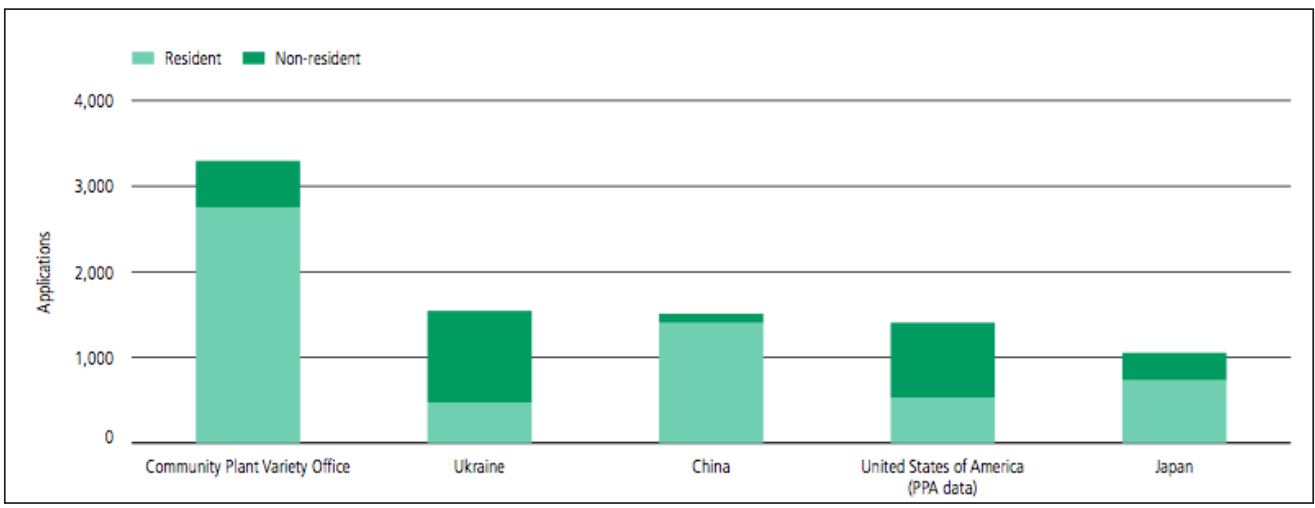

Figura 3. Títulos de obtenciones vegetales por residentes y no residentes en distintas regiones

Fuente: OMPI, 2014 p. 131

Protección de Variedades Vegetales), responsable de la gestión de la protección de obtenciones vegetales en dicho país, en enero de 2015 había 1969 títulos de obtenciones registrados en Brasil. De ellos, 65 títulos corresponden a denominaciones de arroz. Su titularidad pertenece en un $74 \%$ a la empresa pública Embrapa así como a diversos institutos de investigación estatales. Por otra parte, el 12\% de las obtenciones vegetales otorgadas pertenece a empresas nacionales. Solo el 14\% (9 titulares de variedades de arroz) pertenece a empresas multinacionales. En el caso del frijol, simplemente no existen títulos a nombre de empresas extranjeras. En cambio, existen 50 títulos (el 78\%) a favor de institutos de investigación estatales y de Embrapa, siendo el 22\% de titularidad de empresas nacionales. En conclusión, todas las variedades de frijol y el $86 \%$ de las variedades de arroz registradas en Brasil son públicas o nacionales.

Del análisis de la lista de variedades vegetales registradas en Brasil se desprende que los titulares de arroz y frijoles son predominantemente nacionales. Por otro lado, los productos destinados a la exportación como la caña de azúcar y la soja, presentan distintos resultados. Además, la tasa de utilización de las semillas es mucho menor que en los granos (16\%) y el arroz (40\%) en comparación con la soja (65\%) y el maíz (88\%). Además, destacar que la caña de reproducción vegetativa utiliza más clones.

Según los datos del SNPC, en enero de 2015 constan 105 títulos de obtenciones vegetales de caña de azúcar, de los cuales el $30 \%$ son de titularidad de empresas nacionales y el $30 \%$, de empresas multinacionales. Embrapa no tiene antecedentes de registros, pero las universidades federales y los institutos de investigación del Estado representan el $40 \%$ de los titulares, con 42 variedades protegidas.

Ciertamente, la soja es la especie que cuenta con más registros en la SNPC (598 títulos en total). De ellos el 35\% per- 
tenece a empresas extranjeras y el 30\% a empresas nacionales (Embrapa con la participación del 30\% de los registros y las universidades e institutos de investigación del Estado con solo el 5\%).

Como se observa, se produce una gran participación nacional y del Estado en cuanto a los obtentores encargados de investigar e implementar las nuevas variedades. En particular destacan las Instituciones de Ciencia y Tecnología, las universidades públicas, así como los institutos de investigación, incluyendo la empresa Embrapa. Sin embargo, la cantidad de títulos y certificados de obtenciones vegetales generados en Brasil, un país ampliamente orientado al sector agroalimentario y destacado en su perfil en investigaciones agrarias, resulta muy pequeña si la comparamos, por ejemplo, con la cantidad de títulos concedidos en el ámbito de la Unión Europea.

En otro orden de cosas, la historia de la investigación y empleo de productos genéticamente modificados en Brasil presenta matices legales y políticos de interés. La comercialización de este tipo de productos fue regulada inicialmente mediante la Ley 8974, de 5 de enero 1995, de Bioseguridad, que estableció las directrices para la investigación en biotecnología en el país, constituyéndose al tiempo la Comisión Técnica Nacional de Bioseguridad (CTNBio), hoy reestructurada por la actual Ley 11.105 de 24 de marzo de 2005.

La perspectiva general de las plantas modificadas genéticamente aprobadas para la comercialización por la CTNBio tiene un importante campo de desarrollo para las multinacionales. En diciembre de 2014, la variedad vegetal líder en el campo de los OMG autorizados era el maíz (21), seguido por el algodón (12) y la soja (5). No obstante, las 38 autorizaciones han sido concedidas a favor de multinacionales: Monsanto, Bayer, Syngenta, Dow AgroSciences y DuPont. Solo la soja (cuyo nombre comercial es «Cultivance») se ha otorgado a favor de la asociación formada entre BASF y Embrapa (empresa pública brasileña).

Por lo tanto, existen amplias diferencias entre la lista de plantas modificadas genéticamente autorizadas para su comercialización por la CTNBio y los casos de obtenciones vegetales registradas.

Es evidente que Brasil posee un enorme potencial y grandes atractivos para el desarrollo de la biotecnología aplicada a la agricultura, tanto desde la perspectiva del potencial de la agro-biodiversidad, la calidad y cantidad disponible de suelo fértil, como desde el punto de vista agroclimático (clima favorable para el cultivo). La investigación en materia de fito-mejoramiento vegetal viene siendo realizada predominantemente por las instituciones públicas, pero las mismas carecen de estrategias eficaces de distribución de la producción obtenida. Tampoco se perciben sustanciales mejoras en los ingresos de los pequeños agricultores ni de las empresas nacionales productoras de semillas mejoradas.

Por lo tanto, las variedades vegetales registradas (obtenciones vegetales) en 
Brasil, representan una gran parte de la investigación pública encabezada por Embrapa, las universidades federales y estatales, y los Institutos de investigación. Sin embargo, la realidad del mercado es muy diferente. El cuello de botella se sitúa en la fase de producción de estas variedades vegetales. Así, si bien algunas de dichas variedades registradas son efectivamente comercializadas en el mercado para su uso por los agricultores, la comercialización de variedades transgénicas de semillas todavía se concentra en las grandes multinacionales.

\section{CONCLUSIONES}

1. La ingeniería genética y la biotecnología aplicada constituyen sectores considerados como el principal motor del cambio tecnológico del presente siglo, pues son susceptibles de generar profundos efectos sobre el desarrollo económico y social de los países y la población. De hecho, pueden y deben contribuir a abordar los grandes retos que afronta la humanidad en las próximas décadas, sobre todo vinculados al sector agrario y ambiental: incremento de la productividad y la calidad de la producción agrícola con miras a lograr cotas elevadas de seguridad alimentaria, mejoras en la salud de la población, avances en la protección y conservación del medio ambiente, apoyo a la lucha contra el cambio climático, etc.

2. No resulta aconsejable entorpecer ni impedir los avances y progresos en dichas novedosas tecnologías, siempre que sea en el beneficio colectivo de la humanidad. No obstante, sí procede mantener una adecuada y permanente actualización y control sobre el conocimiento en profundidad de los conceptos y elementos básicos de dichas tecnologías, sobre las potencialidades y beneficios esperables, así como acerca de los riesgos que comportan para la salud humana y animal, el medio ambiente y la sociedad en general. A tales fines, cabe apostar por una regulación jurídica internacional uniforme, potente y eficaz en el marco de la moderna sociedad globalizada.

3. Los sistemas jurídicos de protección de la propiedad industrial sobre plantas, material biológico y nuevas variedades vegetales coadyuvan al desarrollo de la investigación en materia de mejora y biotecnología vegetal, incluido el campo de la modificación genética de plantas (OMG) realizada mediante técnicas de ingeniería genética. El consenso mundial en esta materia deberá provenir de los acuerdos internacionales en el seno de la OMPI y sobre todo de la UPOV. Puede resultar aconsejable y necesario el mantenimiento de una doble, pero diferenciada protección legal de la innovación agrícola aplicada a las mejoras vegetales o a la obtención de nuevas variedades. Así, la coexistencia entre el sistema de patentes (biotecnológicas) y el sistema sui géneris de obtenciones vegetales deberá consolidarse. Para ello habrá que definir con total nitidez el objeto legal de la protección: a una nueva 
variedad vegetal que presente un genotipo diferenciado de las variedades preexistentes, le debe corresponder la protección que confiere el título de obtención vegetal, con exclusión de la patente; y a cualquier mejora biotecnológica implementada en un material vegetal (modificación de un solo gen de la variedad que despliegue una función determinada) que no consista en la "generación" de una nueva variedad vegetal en sí misma considerada, le corresponderá el derecho de patente con exclusión de la obtención vegetal.

4. La clara distinción "teórica" entre el sistema de patente y el de obtención vegetal parece no quedar tan nítidamente determinada en Brasil, al menos en el marco de ciertas interpretaciones jurisprudenciales que parecen albergar la posibilidad de una duplicidad de protecciones en el caso de variedades vegetales transgénicas. Estimamos que no debería ser la técnica empleada para la generación de la nueva variedad vegetal (transgénesis, ingeniería genética, mejoramiento convencional o tradicional...) la que determinara el modelo de protección jurídica (patente/obtención), sino el alcance y resultado final del proceso: si se obtiene una nueva variedad, se aplica el sistema de obtención vegetal (conforme al Convenio UPOV); si se logra una mejora que no supone la creación de una nueva variedad, cabría aplicar la patente. Esta cuestión, en regiones del mundo como la Unión Europea, ha quedado ciertamente reflejada y plasmada en las normas jurídicas del derecho comunitario, e internas de los Estados miembros. A ello cabe añadir el constante y decidido impulso de las instituciones comunitarias hacia las políticas centradas en los avances tecnológicos y la sociedad del conocimiento, no solo en el sector agroalimentario y ambiental-climático, sino abarcando la totalidad de sectores potencialmente afectados y beneficiarios de los progresos científicos aplicados.

\section{REFERENCIAS BIBLIOGRÁFICAS}

Amat Llombart, P. (2001). Régimen jurídico del derecho de obtentor de variedades vegetales a la luz de la ley 3/2000, de 7 de enero. Revista General de Derecho, (676-677), pp. 607-627.

Amat Llombart, P. (Coord.) (2007). La propiedad industrial sobre obtenciones vegetales y organismos transgénicos. Valencia: Tirant lo Blanch.

Amat Llombart, P. (2008). Derecho de la biotecnología y los transgénicos (Especial referencia al sector agrario y alimentario). Valencia: Tirant lo Blanch.

Amat Llombart, P. (2011). Política legislativa, estrategias y normativa sobre el cambio climático, medio ambiente y agricultura. En Amat Llombart, P. Derecho agrario, agroalimentario y del desarrollo rural (pp. 119 144). Valencia: Tirant lo Blanch.

Araújo, J. C. (2010). A Lei de Proteção de cultivares. Análise de sua formulação e conteúdo (série memória e análise de leis n. 1). Brasília: Ed. Câmara.

Barrigossi, J. A. F., Lanna, A. C., Ferreira, E. (2004). Agrotóxicos no Cultivo do Arroz no Brasil: análise do consumo e medidas para reduzir o impacto ambiental negativo. Circular Técnica Embrapa, (67). 
Benthien, P. F. (2008). Transgenia e Nanotecnologia. Uma reflexão acerca da relacão entre Modernidade, Novas Tecnologias e Informacão. Revista Theomai, (18). http://www.revista-theomai.unq.edu.ar/numerol8/Faraco.pdf

Bianconi, G. (2013). AS-PTA. Agricultura Familiare Agroecologia. Boletín, (634). http://aspta.org. br/campanha/634-2/.

Bulsing, A. C.; Aviani, D. M.; Pacheco, L. G. A. y Machado, R. Z. (2010). Proteção de Cultivares. En Luiz Otávio Pimentel (Org.). Curso de Propriedade Intelectual e Inovação no agronegócio. Vol. 1 (pp. 258-273). EaD: UFSC.

Camacho, R. (2010). Monográfico. Relevancia de la biotecnología en España. Nota d'economia, (97-98), pp. 33-41.

CPVO (2015). Community Plant Variety Office statistics in 31/12/2015. http://www.cpvo.europa. eu/statistiques/CPVO _ statistics _ summary_2015.pdf

CPVO (2015.a) Community Plant Variety Office. Total applications 1995-2016. http://www. cpvo.europa.eu/main/es/home/about-thecpvo/statistics

Ferreira, J. (2013). Brasil é o segundo maior produtor de OGM do mundo. Epochtimes. 19/06/2013. http://www.epochtimes.com.br/ brasil-e-o-segundo-maior-produtor-de-ogms-do-mundo/\#.Vtbh-kCsQjE. También en AS-PTA. Agricultura Familiar e Agroecología. Boletín, (634), 28 junio 2013. http://aspta.org. br/campanha/634-2/.

James, C. (2015). 20th Anniversary of the Global Commercialization of Biotech Crops (1996 to 2015) and Biotech Crop Highlights in 2015. ISAAA Brief, (51), ISAAA: Ithaca, New York, pp. 2, 3, 6, 9 y 10 .

Martín Uranga, a. (2003). La protección jurídica de las innovaciones biotecnológicas. Especial consideración de su protección penal. Granada: Comares.
Melo, P. G., Morais, O. P. y Diniz, J. A. (2007). Cruzamentos entre cultivares de arroz adaptadas à agricultura familiar. En Anais Congresso Brasileiro de Melhoramento de Plantas. São Lourenço: Sociedade Brasileira de Mel horamento de Plantas.

Melo, P. G., Morais, O. P., Diniz, J. A., Lobo, V. L., Bresegghello, F., Fonseca, J. R., Castro, A. P., Bassinello, P. Z. y Castro, E. M. (2009). BRSGO Serra Dourada: Cultivar de Arroz para a Agricultura Familiar de Goiás, Comunicado Técnico Embrapa, (177), pp. 1-4.

Ministério da Agricultura, Pecuária e Abastecimento (MAPA) (2011). Secretaria de Desenvolvimento Agropecuário e Cooperativismo. Proteção de Cultivares no Brasil. Brasília: Mapa/ ACS.

Ministério do Desenvolvimento Agrário. Programa Nacional de Alimentação Escolar. http://www. mda.gov.br/sitemda/secretaria/saf-ali/sobreo-programa [Consulta: abril 2015].

Nova Cana (2014). 69\% de toda cana plantada no Brasil na safra 2014/15 são variedades RB. http://www.novacana.com/n/cana/variedades/variedades-rb-respondem-plantiocana-191114/ [Consulta: septiembre 2014].

OMPI (2014). World Intellectual Property Indicators. Economics y statistics series. http://www.wipo. int/ipstats/en/wipi [Consulta: julio 2015].

Quintana Carlo, I. (1995). El reglamento CE número 2100/1994 relativo a la protección comunitaria de las obtenciones vegetales. Actas de derecho industrial $y$ derecho de autor, (16), pp. 81-108.

Quintana Carlo, I. (1999). El nuevo régimen jurídico de las obtenciones vegetales (comentario de urgencia a la Ley 3/2000, de 7 de enero). Actas de derecho industrial y derecho de autor, (20), pp. 309-332.

Sánchez Gil, O. (1998). Efectos de la Convención UPOV sobre la patentabilidad de las inven- 
ciones vegetales en el derecho europeo y en particular en los derechos nacionales español y alemán. Derecho de los Negocios, (98), pp. 11-24.

Santilli, J. (2009). Agrodiversidade e direitos dos agricultores. São Paulo: Peirópolis.
Santos, N. D. (2012). O sistema de proteção das cultivares e desenvolvimento sustentável. En Plaza, C. M. y Del Nero, P. A. (Coords.). Proteção jurídica para as ciências da vida. Propriedade Intelectual e Biotecnologia (pp. 173-200). São Paulo: Instituto Brasileiro de Propriedade Intelectual. 